\title{
Resiliensi Akademik dengan Kepuasan Belajar Online pada Mahasiswa
}

\author{
Nelia Afriyeni', Tri Rahayuningsih ${ }^{2 *}$, Erwin $^{3}$ \\ 1,2Prodi Psikologi Fakultas Kedokteran, Universitas Andalas \\ ${ }^{3}$ Prodi Antropologi FISIP, Universitas Andalas \\ Kampus UNAND Limau Manis, Padang, Indonesia \\ neliaafriyeni@med.unand.ac.id, trirahayuningsih@med.unand.ac.id
}

\begin{abstract}
Abstrak
Pandemi Covid-19 berdampak pada mahasiswa belajar dari rumah secara online (daring) selama masa karantina dapat menurunkan motivasi mahasiswa karena kepuasan belajar menjadi terganggu akibat literasi digital yang rendah dan penyesuaian belajar saat di rumah. Masalah-masalah psikologis juga timbul, sehingga dibutuhkan ketahanan psikologis menghadapi situasi yang tidak menyenangkan dan kemampuan beradaptasi, yaitu resiliensi akademik untuk menjadi faktor kepuasan belajar online pada mahasiswa selama pandemi Covid-19. Tujuan penelitian ini adalah untuk mengetahui hubungan resiliensi akademik dengan kepuasan belajar online pada mahasiswa selama proses pembelajaran jarak jauh. Metode penelitian dibagi dalam dua tahap yakni secara kualitatif melalui 19 buah pertanyaan terbuka kepada 11 orang mahasiswa untuk merumuskan konstruk pengukuran dan secara kuantitatif menguji validitas aitem pengukuran tersebut dengan program SPSS pada 116 mahasiswa melalui survei google form. Dari hasil uji korelasi pearson sebesar 0.473 dan $\mathrm{P}<0.000$, maka diperoleh hubungan antara resiliensi akademik dengan kepuasan belajar online, sehingga kesimpulan penelitian ini yaitu hipotesa diterima. Hasil penelitian ini bermanfaat bagi mahasiswa untuk meningkatkan faktor-faktor kepuasan selama belajar dari rumah, salah satunya melalui faktor resiliensi, yang akan dibahas pada tulisan ini.
\end{abstract}

Kata kunci: Kepuasan Belajar Online, Resiliensi Akademik, Pandemi Covid-19

\begin{abstract}
The Covid-19 pandemic has an impact on students studying from home online during the quarantine period, which can reduce student motivation because learning satisfaction is disrupted due to low digital literacy and learning adjustments at home. Psychological problems also arise, so it requires psychological resilience to face unpleasant situations and adaptability, namely academic resilience to become a factor of online learning satisfaction for students during the Covid-19 pandemic. The purpose of this study was to determine the relationship between academic resilience and online learning satisfaction among students at the Andalas University (UNAND) Psychology Study Program during the distance learning process. The research method is divided into two stages, namely qualitatively interviewing 10 students to formulate a measurement construct and quantitatively testing the validity of these measurement items with the SPSS program on 116 students through a google form survey. From the results of the Pearson correlation test of 0.473 and $\mathrm{P}<0.000$, it is found that the relationship between academic resilience and online learning satisfaction is obtained, so that this study concludes that the hypothesis is accepted. The results of this study are useful for students to increase the satisfaction factors while studying from home, one of which is through the resilience factor, which will be discussed in this paper.
\end{abstract}

Keywords: Online Learning Satisfaction, Academic Resilience, the Covid-19 Pandemic

\section{PENDAHULUAN}

Kuliah online atau sistem dalam jaringan daring merupakan cara yang lebih maju dalam lembaga akademik tradisional. Kehilangan fokus merupakan alasan yang paling banyak dikutip mengapa mahasiswa yang tidak berhasil dalam kuliah secara daring dan mengerjakan tugas sesuai jadwal (Bauer, 2019), sehingga dosen harus kreatif dalam mendesain aktifitas 
perkuliahan meskipun tidak mengerjakannya secara langsung di kampus. Efektifitas pembelajaran belajar online ini dapat dilihat dari tingkat kepuasan belajar siswa, hal ini senada dengan yang diungkap oleh Cheok dan Wong (2015) bahwa kepuasan belajar online merupakan salah satu penentu apakah sistem pembelajaran online (e-learning) dapat digunakan berkelanjutan.

Menurut Kuo et al.,(2013) kepuasan belajar online mengacu pada persepsi mahasiswa tentang pengalaman belajar dan nilai yang dirasakan dari suatu kegiatan pembelajaran. Hal senada juga di sampaikan oleh Rodriguez (2015) bahwa kepuasan belajar online merupakan persepsi, dan ekspektasi, peserta didik terhadap pembelajaran online. Kepuasan mahasiswa terkait dengan beberapa variabel seperti ketekunan, kemampuan peserta didik untuk mengingat materi pembelajaran, dan keberhasilan peserta didik dalam pembelajaran (Kuo., Walker., Belland., \& Schroder., 2013). Kepuasan belajar online akan menujukkan sejauh mana pengguna atau mahasiswa yakin bahwa sistem pembelajaran online memenuhi syarat pembelajaran yang informatif dan komunikatif (Cheok \& Wong, 2015). Sehingga, kepuasan belajar online merupakan salah satu indikator yang dapat dijadikan acuan untuk meningkatkan kualitas pembelajaran online (Rodriguez, 2015). Kepuasan belajar juga merupakan faktor penting yang bisa mempengaruhi tingkat motivasi mahasiswa dan sebagai faktor psikologis dalam keberhasilan akademik, termasuk kepada pembelajaran jarak jauh (Ikhsan et al., 2019).

Sebagai salah satu aplikasi belajar jarak jauh, Webinar dan platform kolaborasi virtual, memungkinkan keuntungan pembelajaran tatap muka dengan pertukaran interaktif secara realtime. Literatur saat ini menunjukkan bahwa webinar adalah alat yang dapat diandalkan untuk menyampaikan interaksi yang hampir normal antara audiens dan dosen (Sleiwah et al., 2020). Namun, mayoritas mahasiswa lebih memilih pembelajaran tatap muka daripada secara online, meski pembelajaran online tetap dianggap bermanfaat dan memuaskan. Padahal, jika didesain yang bagus, pembelajaran online tidak hanya menjadi sekedar alternatif pembelajaran jarak jauh, tetapi juga lebih baik daripada pengajaran tradisional di kelas (Amado et al., 2019). Survei umpan balik menunjukkan kepuasan belajar online yang tinggi (Alhazzani, 2020), dipengaruhi oleh instruktur (dosen) terhadap hasil belajar dan kepuasan pengguna (mahasiswa) yang merujuk pada motivasi. Menurut Meneghel et al., (2019) cara untuk meningkatkan kepuasan belajar adalah dengan membangun resiliensi siswa yang bisa dilakukan melalui strategi koping. Bahkan resiliensi akademik dianggap sebagai indikator penyesuaian sekolah serta prediktor kuat partisipasi mahasiswa mengikuti perkuliahan dan motivasi belajar (Anghel, 2015)

Fakta bahwa pandemi Covid-19 telah memengaruhi kesehatan mental para civitas akademik menjadi kebutuhan mendesak, terkait pemahaman terhadap informasi pengembangan program berupa tindakan dan pesan kesehatan masyarakat guna mendukung mahasiswa yang mengalami krisis resiliensi (Zhai \& Du, 2020). Selama masa pandemi Covid-19 ini dosen harus bekerja lebih keras untuk menanamkan strategi yang mendukung kesejahteraan mahasiswa dan juga menumbuhkan ketahanan emosional (resiliensi), ke dalam kurikulum mereka (Carolan et al., 2020). Ketidaknyamanan mahasiswa karena literasi digital yang terbatas dan tidak adanya keterlibatan manusia secara fisik (Carolan et al., 2020) membutuhkan ketangguhan atau resiliensi untuk mengatasi stres agar tetap seimbang (Vinkers et al., 2020). Pembelajaran daring yang fleksibel adalah peluang kunci untuk membangun resiliensi, tetapi Universitas tidak boleh meremehkan pentingnya interaksi tatap muka antara staf, dosen dan peserta didik (Dohaney et al., 2020). Studi ini memberikan titik awal yang kuat bagi peneliti untuk memahami bagaimana Universitas dapat menumbuhkan resiliensi terhadap gangguan pengajaran yang dialami berbagai Universitas akibat pandemi Covid-19, sehingga mahasiswa tetap bisa merasakan kepuasan dari pengalaman belajar online. 
Resiliensi pada bidang pendidikan, dianggap sebagai kemampuan untuk secara efektif menghadapi kemunduran, dan tekanan dalam lingkungan akademik. Dalam kondisi gangguan atau bencana pandemi seperti saat ini, lingkungan online yang bermakna sebagai 'pos tujuan' pertama menuju resiliensi, bahkan jika ruang online hanyalah sebuah alternatif untuk kegiatan tatap muka (penyampaian ceramah, bacaan, dan penilaian) dapat mendorong pendekatan unik, untuk meningkatkan keterlibatan mahasiswa dan mempertahankan komunikasi dengan dosen (Dohaney et al., 2020). Dengan demikian, resiliensi akademik dianggap mampu untuk mempertahankan kepuasan belajar online pada mahasiswa. Oleh karena itu, tujuan penelitian ini untuk mengetahui gambaran kepuasan belajar online berdasarkan resiliensi akademik pada mahasiswa Prodi Psikologi Universitas Andalas dalam menghadapi pandemik Covid-19.

\section{METODE}

Penelitian ini merupakan uji korelasi antara kepuasan belajar online dengan resiliensi mahasiswa menghadapi wabah Covid-19. Subjek dalam penelitian ini adalah 116 orang mahasiswa Prodi Psikologi Unand (Universitas Andalas) dengan karakteristik sampel adalah mahasiswa yang pernah mengalami belajar tatap muka di kelas, dan saat ini sedang mengikuti perkuliahan jarak jauh (online). Pengumpulan data dilakukan dengan menggunakan dua skala. Pertama skala Kepuasan belajar online dengan 33 aitem, yang didasarkan pada aspek-aspek kepuasan belajar online, meliputi User Quality, Organizational Quality, E-Learning System Quality (Cheok \& Wong, 2015), dengan koefisien alpha cronbach sebesar 0.917. Sedang skala Resiliensi Akademik dengan 41 aitem, disusun berdasarkan aspek Perseverance, Refelecting and adaptive help seeking, negative affect and emotional response (Cassidy, 2016), Untuk alpha cronbach skala resiliensi akademik sebesar 0.907 .

\section{HASIL}

Melalui hasil analisis product moment, dapat di ketahui bahwa nilai signifikansi $(0,000<$ $0,05)$ dengan $r=0,473$. Hasil ini menunjukkan bahwa ada hubungan antara resiliensi akademik dengan kepuasan belajar online. Hasil $\mathrm{r}$ / pearson correlation yang positif mengungkap bahwa individu yang memiliki resiliensi akademik yang baik akan memiliki kepuasan belajar online yang baik pula. Dengan hasil ini berarti hipotesis yang di ajukan dapat diterima, Artinya, semakin besar kemampuan resiliensi akademik mahasiswa, maka semakin tinggi pula kecenderungan kepuasan belajar online pada pandemi Covid-19 ini, begitu juga sebaliknya

\section{DISKUSI}

Hasil penelitian menunjukkan ada hubungan resiliensi akademik dengan kepuasan belajar online pada mahasiswa Prodi Psikologi UNAND selama belajar dari rumah pada masa pandemi. Hal ini sejalan dengan beberapa temuan yang mengungkapkan hal yang sama bahwa resiliensi akan memprediksi munculnya kepuasan belajar individu (Kumalasari \& Akmal, 2020; Meneghel et al., 2019). Kumalasari dan Akmal (2020) menambahkan pada situasi pandemic, resiliensi di perlukan untuk meningkatkan kepuasan belajar individu yang dilakukan secara online, namun demikian hubungan ini membutuhkan kematangan dari kesiapan belajar daring oleh siswa. Pada individu yang telah memiliki kesiapan belajar, maka resiliensi akan mudah terbentuk dan dapat meningkatkan kepuasan belajar. Dalam mempromosikan kepuasan dan kinerja akademik, individu perlu membangun ketahanan akademik melalui strategi koping (Meneghel et al., 2019), penelitiannya juga menengaskan bahwa ketahanan akademik dapat mempromosikan kepuasan akademik pada siswa. 
Penelitian Kuo, Walker, Belland, dan Schroder (2013) ada beberapa hal yang dapat mempengaruhi kepuasan individu dalam situasi belajar online, interaksi mahasiswa dan dosen, interaksi mahasiswa dan kemudian yang paling strategis adalah, Internet Self-Efficacy mengacu pada keyakinan bahwa mahasiswa mampu mengatur dan melaksanakan perkuliahan terkait internet yang diperlukan untuk menyelesaikan tugas yang diberikan. Individu dengan self efficacy yang baik biasanya memiliki resiliensi yang kuat pula dalam menghadapi masalah (Sagone \& Caroli, 2013). Remaja Tangguh atau yang memiliki resiliensi tinggi dicirikan dengan individu pemikir yang mampu memecahkan masalah konkret dengan cara mereka sendiri, mengontraskan kekakuan sistem, mengadopsi strategi berorientasi tugas, dan memaksimalkan perubahan (Sagone \& Caroli, 2013). Hal ini tentu di perlukan pada situasi baru seperti belajar online. Dengan kata lain, resiliensi atau ketangguhan siswa dalam belajar di perlukan untuk mempromosikan kepuasan. Meskipun sedikit berbeda beberapa penelitian sebelumnya juga menyampaikan bahwa resiliensi dapat mengungkapkan kepuasan pada jurusan kuliah yang dipilih (Ebulum, 2016; Nam \& Kim, 2018) maupun kepuasan dengan kehidupan kuliah (Nam \& Kim, 2018).

Menurut hasil penelitian yang dilakukan oleh Yasir et al., (2017) peserta didik yang merasakan kepuasan dalam pembelajaran akan mempunyai motivasi dan minat belajar yang tinggi, serta mempunyai hasil belajar yang baik. Kepuasan belajar online juga berhubungan dengan bagaimana pengalaman peserta didik dalam mengikuti pembelajaran online, bahwa semakin positif pengalaman yang dirasakan, maka mahasiswa akan merasakan kepuasan dalam pembelajaran online (Deshwal et al., 2017). Namun, Sadikin dan Hamidah (2020) menyebutkan bahwa kendala sinyal yang lemah, kesulitan dalam membeli kuota dapat menurunkan kepuasan belajar online. Sementara kendala dari segi pelayanan institusi pendidikan berupa instruksi dosen yang kurang jelas, dan dosen yang kurang menguasai media belajar online (Lestiyanawati \& Widyantoro, 2020) serta kurang dalam memanajemen kelas online (Rosali, 2020). Menurut Handayani (2020) adanya ketidakpuasan dengan interaksi termasuk komunikasi dengan pengajar dan teman sekalas serta kurangnya umpan balik dalam kelas online yang dirasakan peserta didik karena kurang nya resiliensi siswa.

Cassidy (2016) menyebutkan bahwa resiliensi akademik adalah kemampuan individu untuk meningkatkan keberhasilan dalam pendidikan walaupun dalam situasi sulit. Resiliensi diperlukan untuk dapat mengatasi tekanan dampak pandemi covid-19 dan pulih ke tingkat fungsi normal. Resiliensi sangat penting untuk menghadapi tantangan saat ini bersama-sama dalam level komunitas, termasuk dalam bidang pendidikan (Vinkers et al., 2020). Resiliensi dimaknai sebagai konsep ketahanan dengan penekanan pada bagaimana program pendidikan dapat menumbuhkan ketangguhan mahasiswa. Menurut Cassidy (2016), resiliensi akademik adalah kemampuan individu untuk meningkatkan keberhasilan dalam pendidikan walaupun dalam situasi sulit. Dengan kata lain resiliensi merupakan ketahanan yang dibutuhkan pada diri mahasiswa untuk mampu beradaptasi menghadapi situasi sulit dan menekan di lingkungan akademik dengan berusaha menunjukkan dan mengembangkan potensi dirinya menjadi lebih baik termasuk pada masa pandemi.

\section{KESIMPULAN}

Kesimpulan penelitian ini yaitu ada hubungan antara resiliensi akademik dengan kepuasan belajar online pada mahasiswa Prodi Psikologi UNAND. Dengan diterimanya hipotesa penelitian, maka untuk menjaga motivasi mahasiswa selama belajar dari rumah yakni melalui kepuasan belajar online, dapat ditingkatkan dengan faktor resiliensi akademik. Peran dosen 
sebagai fasilitator dan ketersediaan fasilitas wifi di rumah juga turut menunjang kepuasan belajar online mahasiswa.

\section{UCAPAN TERIMA KASIH}

Terima kasih penulis ucapkan pada LPPM Universitas Andalas yang telah memberikan dukungan pendanaan penelitian dosen pemula ini sehingga berjalan lancar dan terselesaikan dengan baik. Terima kasih juga atas bimbingan Prof. Erwin atas saran dan arahan nya terhadap proses penelitian ini.

\section{DAFTAR PUSTAKA}

Alhazzani, N. (2020). MOOC's impact on higher education. Social Sciences \& Humanities Open, 2(May), 1-11. https://doi.org/10.1016/j.ssaho.2020.100030

Amado, C. M., Minahk, C. J., Cilli, E., Oliveira, G., \& Dupuy, F. G. (2019). Jo ur 1 P re. BBA - Biomembranes, 183135. https://doi.org/10.1016/j.bbamem.2019.183135

Anghel $^{\text {a }, ~ R . ~ E . ~(2015) . ~ P s y c h o l o g i c a l ~ a n d ~ E d u c a t i o n a l ~ R e s i l i e n c e ~ i n ~ H i g h ~ v s . ~ L o w-R i s k ~}$ Romanian Adolescents. Procedia - Social and Behavioral Sciences, 203, 153-157. https://doi.org/10.1016/j.sbspro.2015.08.274

Bauer, M. (2019). Translating a Successful Lecture into Online Course Content-Experiences of a Control Engineering Lecturer. IFAC-PapersOnLine, 52(9), 312-317. https://doi.org/10.1016/j.ifacol.2019.08.220

Carolan, C., Davies, C. L., Crookes, P., McGhee, S., \& Roxburgh, M. (2020). COVID 19: Disruptive impacts and transformative opportunities in undergraduate nurse education. Nurse Education in 102807. https://doi.org/10.1016/j.nepr.2020.102807

Cassidy, S. (2016). The Academic Resilience Scale (ARS-30): A new multidimensional construct measure. Frontiers in Psychology, 7(NOV), 1-11. https://doi.org/10.3389/fpsyg.2016.01787

Cheok, M. L., \& Wong, S. L. (2015). Predictors of E-learning satisfaction in teaching and learning for school teachers: A literature review. International Journal of Instruction, 8(1), 75-90. https://doi.org/10.12973/iji.2015.816a

Deshwal, P., Trivedi, A., \& Himanshi, H. L. N. (2017). Online Learning Experience Scale Validation and Its Impact on Learners' Satisfaction. Procedia Computer Science, 112, 2455-2462. https://doi.org/10.1016/j.procs.2017.08.178

Dohaney, J., de Róiste, M., Salmon, R. A., \& Sutherland, K. (2020). Benefits, barriers, and incentives for improved resilience to disruption in university teaching. International Journal of Disaster Risk Reduction, 50. https://doi.org/10.1016/j.ijdrr.2020.101691

Ebulum, G. C. (2016). Resilience, Gender and Age as Predictors of Satisfaction with Academic 
Major among University Undergraduates. International Journal of Research in Engineering and Social Sciences, 6(04), 13-23.

Handayani, L. (2020). Keuntungan, Kendala dan Solusi Pembelajaran Online Selama Pandemi Covid-19: Studi Ekploratif di SMPN 3 Bae Kudus. Journal Industrial Engineering \& Management Research, 1(2), 16.

Ikhsan, R. B., Saraswati, L. A., Muchardie, B. G., Vional, \& Susilo, A. (2019). The determinants of students' perceived learning outcomes and satisfaction in BINUS online learning. Proceedings of 2019 5th International Conference on New Media Studies, CONMEDIA 2019, April, 68-73. https://doi.org/10.1109/CONMEDIA46929.2019.8981813

Kumalasari, D., \& Akmal, S. Z. (2020). Resiliensi akademik dan kepuasan belajar daring di masa pandemi COVID-19: Peran mediasi kesiapan belajar daring. Jurnal Psikologi Indonesia, 9(2). https://doi.org/https://doi.org/10.30996/persona.v9i2.4139

Kuo, Y. C., Walker, A. E., Belland, B. R., \& Schroder, K. E. E. (2013). A predictive study of student satisfaction in online education programs. International Review of Research in Open and Distance Learning, 14(1), 16-39. https://doi.org/10.19173/irrodl.v14i1.1338

Lestiyanawati, R., \& Widyantoro, A. (2020). The Strategies and Problems Faced by Indonesian Teachers in Conducting e-learning during COVID-19 Outbreak. CLLiENT (Culture, Literature, Linguistics, and English Teaching), 2(1), 71-82. https://doi.org/10.32699/cllient.v2i1.1271

Meneghel, I., Martínez, I. M., Salanova, M., \& Witte, H. (2019). Promoting academic satisfaction and performance: Building academic resilience through coping strategies. Psychology in the Schools, 56(6), 875-890. https://doi.org/10.1002/pits.22253

Nam, M. H., \& Kim, H. O. (2018). Effect of Personality and Resilience on Satisfaction with Major in Nursing Students. Journal of Korean Academy of Nursing Administration, 24(4), 298-306. https://doi.org/10.11111/jkana.2018.24.4.298

Rosali, E. S. (2020). Aktifitas Pembelajaran Daring Pada Masa Pandemi Covid-19 Di Jurusan Pendidikan Geografi Universitas Siliwangi Tasikmalaya. Geography Science Education Journal (GEOSEE), 1(1), 21-30. https://www.researchgate.net/publication/340917125_Kendala_Pelaksanaan_Pembelajar an_Jarak_Jauh_PJJ_dalam_Masa_Pandemi/stats

Sagone, E., \& Caroli, M. E. De. (2013). Relationships between Resilience, Self-Efficacy, and Thinking Styles in Italian Middle Adolescents. Procedia - Social and Behavioral Sciences, 92(Lumen), 838-845. https://doi.org/10.1016/j.sbspro.2013.08.763

Sleiwah, A., Mughal, M., \& Roblin, P. (2020). COVID-19 Lockdown Learning: The uprising of Virtual Teaching. Journal of Plastic, Reconstructive \& Aesthetic Surgery. https://doi.org/10.1016/j.bjps.2020.05.032 
Vinkers, C. H., van Amelsvoort, T., Bisson, J. I., Branchi, I., Cryan, J. F., Domschke, K., Manchia, M., Pinto, L., de Quervain, D., Schmidt, M. V., \& van der Wee, N. (2020). Stress resilience during the coronavirus pandemic. European Neuropsychopharmacology, 35, 12-16. https://doi.org/10.1016/j.euroneuro.2020.05.003

Yasir, M., Suarman, S., \& Gusnardi, G. (2017). Analisis Tingkat Kepuasan Siswa dan Motivasi Dalam Pembelajaran Kelompok (Cooperative Learning) dan Kaitannya Dengan Hasil Belajar Akuntansi di SMK Labor Binaan FKIP UNRI Pekanbaru. Jurnal Pekbis, Volume 9(2), 77-90.

Zhai, Y., \& Du, X. (2020). Addressing collegiate mental health amid COVID-19 pandemic. Psychiatry Research, 288(April), 113003. https://doi.org/10.1016/j.psychres.2020.113003 